\title{
Percepções De Tutores Sobre O Assédio Sexual Sofrido Por Jovens Trabalhadores Nas Organizações
}

\section{Perceptions Of Tutors About Sexual Harassment Suffered By Young Workers In Organizations}

\author{
Alice de Freitas Oletoํㅜ José Vitor Palhares², Kely César Martins de Paiva ${ }^{2}$, Letícia Rocha Guimarães ${ }^{2}$ \\ ${ }^{1}$ Fundação Getúlio Vargas, FGV, EAESP, Brasil, ${ }^{2}$ Universidade Federal de Minas Gerais, UFMG, Brasil. \\ Correspondência: Alice de Freitas Oleto. Av. Nove de Julho, 2029, Bela Vista, CEP 01.313-902, São Paulo, SP, \\ Brasil. Telefone: +55 (11) 3799-7777. E-mail: aliceoleto@ hotmail.com.
}

Recebido: 16 de julho de 2018 Aceito: 02 de outubro de 2018 Publicado: 28 de dezembro de 2018

DOI: http://dx.doi.org/10.21714/1679-18272018v16n1.p43-56

\begin{abstract}
Resumo
Os estudos sobre assédio sexual nas organizações ainda são poucos explorados na área da Administração e carecem de problematização quanto ao consentimento, submissão e liberdade dos indivíduos. Assim, o objetivo deste artigo é analisar como são percebidas situações de assédio sexual vivenciadas por jovens trabalhadores sob a perspectiva dos profissionais da Associação Alfa que os assistem e contribuem para sua inclusão no mundo do trabalho. Para tanto, realizou-se um estudo de caso, de natureza exploratória e abordagem qualitativa. A coleta de dados se deu por meio de entrevistas com roteiro semiestruturado com 21 profissionais da Associação, cujos dados foram submetidos à análise de conteúdo. Inicialmente, tentou-se entrevistar os jovens trabalhadores, mas a Associação negou terminantemente qualquer contato com eles. Percebeu-se que os jovens que sofreram assédio sexual são predominantemente do gênero feminino e que a situação vivida traz consequências de natureza pessoal e profissional. Esse tratamento foi percebido como necessário para a desmistificação do tema, assim como para uma compreensão mais clara e desnaturalizada dessa prática nas relações de trabalho, evitando-se a culpabilização da vítima e a banalização da agressão, de modo que experiências dessa natureza não comprometam a desses futuros profissionais.
\end{abstract}

Palavras-chave: Assédio Sexual, Jovens Trabalhadores, Trabalho.

\begin{abstract}
The studies on sexual harassment in organizations are still few explored in the Administration and they need problematization regarding the consent, submission and freedom of the individuals. Therefore, the objective of this paper is to analyze how sexual harassment situations experienced by young workers are perceived from the perspective of the professionals of the Alpha Association, who assist them and contribute to their inclusion in the world of work. Thus, a case study, exploratory in nature and qualitative approach was carried out. The data collection was done through interviews with a semi-structured script with 21 professionals of the Association, whose data were submitted to content analysis. Initially, an attempt was made to interview the young workers, but the Association strictly denied any contact with them. It was noticed that the young people who suffered sexual harassment are predominantly of the feminine kind and that the lived situation brings consequences of personal and professional nature. This treatment was perceived as necessary for the demystification of the subject, as well as for a clearer and more denatured understanding of this practice in the labor relations, avoiding the victim's blame and the trivialization of the aggression, so that experiences of this nature do not compromise the future professionals.
\end{abstract}

Keywords: Sexual Harassment, Young Workers, Work.

Esta obra está licenciada sob uma Licença Creative Commons Attribution 3.0

\section{Introdução}

O mundo do trabalho passou por metamorfoses nas últimas décadas, apresentando características como fluidez do tempo e do espaço, alta competitividade, dinamicidade e flexibilidade, em detrimento de ambientes rígidos e estáticos. Assim sendo, surgiram também novos imperativos para o trabalhador, que cada dia mais é cobrado por 
atualização constante, resiliência e autogestão, sofrendo pressões internas e externas que podem ocasionar sobrecarga e fragilidade física e emocional.

Algumas das consequências para o trabalhador, dada essa realidade organizacional, são possíveis situações de assédio moral e de assédio sexual, sendo este último o foco deste artigo. Conforme Freitas (2001), o assédio moral e o assédio sexual podem estar associados, isto é, o esforço repetitivo de desqualificação de um indivíduo pode conduzir às duas situações. Portanto, é válido esclarecer um conceito de assédio moral, considerado neste estudo como o "conjunto de práticas hostis relacionadas ao exercício de poder, a uma lógica empresarial distorcida e, em alguns casos, a descompensações psicológicas graves de ordem individual” (SCHATZMAM et al, 2009, p. 14), e de assédio sexual, compreendido como um "comportamento indesejado de caráter sexual que se manifesta sob a forma física, verbal ou não verbal, com o objetivo de violar a dignidade da pessoa e de criar um ambiente intimidativo, hostil, humilhante ou ofensivo" (DIAS, 2008, p. 02).

Diferentemente do assédio moral, o assédio sexual é considerado crime, estando previsto no artigo 216-A, caput do Código Penal Brasileiro (BRASIL, 1940). O que é atingido no assédio sexual é a liberdade sexual da vítima, relacionada ao ambiente de trabalho, no sentido de ela não ser importunada por pessoas que se prevalecem da sua condição de superior hierárquico ou de ascendência (GRECO, 2012). No campo da Administração, o assédio sexual é considerado um tipo de assédio moral, pois as relações de poder abusivas tendem a ser mantidas e/ou alimentadas por meio do constrangimento ao favorecimento sexual, mediante a ameaça à permanência do vínculo de trabalho.

A temática do assédio sexual nas organizações tem sido trabalhada em diversas áreas acadêmicas, como por exemplo no Direito (PAMPLONA FILHO, 2005; FELKER, 2006; HIGA, 2016), na Sociologia (TANGRI et al., 1982; DIAS, 2008), na Psicologia (FITZGERALD, 1993; SCHNEIDER et al., 1997) e na Administração (FORD; MCLAUGHLIN, 1988; FREITAS, 1996, 2001). Contudo, embora o fenômeno do assédio sexual nas organizações não seja algo recente, esse tema ainda é pouco discutido e evidenciado nas pesquisas no campo dos estudos organizacionais (FREITAS, 2001), principalmente quando relacionado com jovens trabalhadores, dadas as fragilidades e peculiaridades desse público no que tange a momento de sua inserção no mercado de trabalho, assim como a idade que limita tanto as experiências de vida como as de trabalho, o deixando à mercê de violências de várias ordens (TUCKER;LOUGHLIN, 2006).

Desse modo, o objetivo proposto nesse trabalho é analisar como são percebidas situações de assédio sexual vivenciadas por jovens trabalhadores sob a perspectiva dos profissionais da Associação Alfa que os assistem e contribuem para sua inclusão no mundo do trabalho, em organizações de grande porte e de diversos segmentos. Para atingir o objetivo proposto, foi realizado um estudo de caso, de natureza descritiva e abordagem qualitativa. A coleta de dados deu-se por meio de entrevistas com roteiro semiestruturado, em que foram entrevistados 21 profissionais da Associação Alfa, e os dados coletados foram submetidos à técnica de análise de conteúdo. Ressalte-se que a pesquisa tinha como objetivo inicialmente entrevistar os jovens trabalhadores assistidos pela Associação Alfa, mas tal contato direto não foi autorizado.

De todo modo, o estudo sobre o assédio sexual vivenciados por jovens trabalhadores é relevante, quer seja o assédio praticado contra eles mesmos, quer contra terceiros, pela importância dos jovens na estrutura social e de suas experiências para a formação da massa trabalhadora. Além disso, tema proposto seria uma forma de contribuição ao meio acadêmico, já que o mesmo é relativamente recente, com poucas pesquisas, tanto em relação ao assédio sexual, quanto referente aos jovens trabalhadores. Acrescentam-se, ainda, as dificuldades de se pesquisar sobre um tema tão delicado e importante para as pessoas e para as organizações. Ademais, o presente trabalho poderá gerar a possibilidade de desnudar uma parte da realidade desse público que pode ser alcançada por políticas e práticas de gestão de pessoas nas organizações que a abrigam.

Este artigo está estruturado em cinco seções, a contar desta introdução. A seção seguinte diz respeito ao referencial teórico do estudo, subdividido entre os temas "Assédio Sexual" e "Jovens Trabalhadores". Em seguida, é exposto os procedimentos metodológicos utilizados na condução desta pesquisa. A quarta seção se refere a apresentação e análise dos resultados e, por fim, são tecidas as considerações finais acerca do estudo.

\section{Fundamentação Teórica}

Este capítulo aborda a temática do assédio sexual, apresentando uma análise no ambiente das organizações, além de aspectos jurídicos importantes para o entendimento acerca do tema. Em um segundo momento, trata-se do grupo de jovens trabalhadores, apontando suas peculiaridades e alguns dados relevantes desse público no Brasil.

\section{Assédio Sexual}

As causas da ocorrência do assédio podem ser diversas, desde questões pessoais, como inveja e desgosto de 
outrem, até situações promovidas por uma cultura que favorece e/ou beneficia o agressor em decorrência do alcance de determinada meta/objetivo (NUNES et al., 2018).

O assédio sexual é uma forma de violência física e psicológica, assim como o assédio moral. Em seus casos, a vítima é perseguida no ambiente de trabalho, ou mesmo fora dele, com uma série de investidas de conotação sexual. Em outras palavras, ela recebe, repetidamente e sem seu consentimento, galanteios, olhares libidinosos, propostas, entre outras investidas. O assédio sexual no trabalho pode se configurar sob a ameaça de represália como a remoção, o preterimento em lista de promoção ou mesmo a demissão do emprego (PRATA, 2010).

Para Teixeira e Rampazo (2017), o assédio sexual é a prática de violências não desejadas pela vítima, ocorridas em espaços organizacionais, em relações hierárquicas ou não de trabalho que impliquem, ou não, em reações explícitas de resistência, ou em não reações de resistência em função de o assediador poder punir o assediado, e/ou simplesmente por serem práticas demarcadas por aspectos mais abrangentes de um contexto social de base patriarcal e constituído a partir de performatividades de gênero que colocam a vítima em um lugar simbólico e, por vezes, efetivamente inferior.

Nos Estados Unidos, o assédio sexual é considerado discriminação sexual; na França, é considerado delito somente se houver uma chantagem explícita de demissão (FREITAS, 2001). Já no Brasil, o assédio sexual é considerado crime, com previsão no artigo 216-A do Código Penal Brasileiro (CPB, 1940):

Art. 216-A. Constranger alguém com o intuito de obter vantagem ou favorecimento sexual, prevalecendo-se o agente da sua condição de superior hierárquico ou ascendência inerentes ao exercício de emprego, cargo ou função. Pena detenção, de 1 (um) a 2 (dois) anos.

Ainda que haja respaldo legal e que isto signifique um avanço para a sociedade brasileira, Hirigoyen (2014) sinaliza a dificuldade de um indivíduo, vítima de assédio sexual, fornecer provas de não consentimento à justiça, haja vista situações em que aqueles que assediam tentam inverter o que é dito pelo assediado, invocando o argumento de que eles é quem são vítimas de um golpe, que a vítima é responsável pela tensão sexual por ele sentida.

O assédio sexual apresenta 2 tipos, quais sejam: assédio sexual por chantagem e o assédio sexual por intimidação. De acordo com Barros (1998), o assédio sexual por chantagem traduz exigência formada por superior hierárquico a um subordinado, para que se preste à atividade sexual sob a pena de perder o emprego ou benefícios advindos da relação de trabalho. Já o assédio sexual por intimidação é o mais genérico e caracteriza-se por incitações sexuais inoportunas, uma solicitação sexual ou outras manifestações da mesma índole, verbais ou físicas, com o efeito de prejudicar a atuação laboral de uma pessoa ou de criar uma situação ofensiva, hostil, de intimidação ou abuso no trabalho.

Já Settles et al. (2011) entendem que assédio sexual é definido como comentários ou comportamentos indesejados, podendo ser dividido e três tipos. O primeiro tipo é o assédio por gênero, e refere-se a comportamentos que prejudicam um indivíduo com base em seu gênero, como, por exemplo, comentários que insultam a inteligência das mulheres e comentários sobre comportamentos que um "homem real" faria. O segundo tipo é a atenção sexual indesejada e se apresenta através de toques voluntários ou tentativas de estabelecer uma relação sexual. E o terceiro tipo é a coerção sexual, e refere-se a tentativas de coagir uma relação sexual em troca de ameaças ou benefícios relacionados ao trabalho, como, por exemplo, prometer uma promoção se a vítima se envolver em atividades sexuais.

Forster (1992) apresenta algumas atitudes que podem constituir assédio sexual: contato físico não desejado, solicitação de favores sexuais em troca de promoção, adiantamentos ou proposições sexuais indesejáveis, continuação de sugestões de atividade social fora do local de trabalho depois de ter sido esclarecido que tal sugestões não são bem-vindas, flertes ofensivos, insinuações ou comentários obscuros, exibição calendários sexualmente sugestivos, agressão sexual, comentários ofensivos sobre aparência ou vestimenta relacionadas ao gênero,e comportamento sexista ou condescendente.

O crime de assédio sexual consuma-se quando o agente constrange a vítima, independentemente da efetiva obtenção da vantagem ou favorecimento sexual visados. Além disso, a tentativa é possível por se tratar de um crime que costuma se realizar por meio de vários atos. É o que ocorre, por exemplo, quando o assédio sexual tenha sido tentado na forma escrita, cuja correspondência, em razão de extravio, chega às mãos de terceira pessoa. (GRECO, 2012)

Hirigoyen (2014) afirma que o tipo de assédio sexual mais frequente é aquele que o comportamento sedutor do assediador é ambíguo, isto é, num primeiro instante, o assediador se mostra atencioso, quase paternal, ou seja, uma pessoa confiável. Nesse momento, normalmente, a vítima só consegue perceber que há uma familiaridade um pouco exagerada por parte do superior hierárquico. Em sequência, e à medida que a vítima não consegue compreender as reais intenções do assediador, levando-a a se sentir confusa e desconcertada, o assediador se apega 
nessas ambivalências e inicia um comportamento mais insistente, até a imposição sexual.

É importante salientar que o sujeito assediador ocupa, muitas vezes, posição hierárquica superior no ambiente de trabalho ou que seja detentor de condições que prejudiquem o assediado nas suas funções ou, ainda, na possibilidade de perder o emprego. Vale lembrar que, até mesmo por questões históricas e culturais, a regra é que o homem seja o assediador, mas não há qualquer impedimento de que a mulher ocupe tal posição. Ademais, o assédio pode ocorrer entre pessoas de sexos diferentes ou até mesmo entre pessoas do mesmo sexo; afinal, não se trata de uma questão de cunho puramente sexual ou de orientação sexual, mas de uma relação de poder. O elemento ativo abusa de sua condição superior para conseguir vantagem sexual em detrimento do assediado. Já o sujeito passivo pode ser um homem ou uma mulher, empregado ou funcionário público, assediado no trabalho ou em razão deste, por sujeito com condição superior de mando, se vendo ameaçado seu emprego, benefícios e sua liberdade sexual (SANTOS, 2002).

Brunner e Dever (2014) entendem que o assédio sexual é entendido como um mecanismo através do qual o poder é promulgado entre os indivíduos para criar e manter o controle da sexualidade e, especificamente, para exigir um desempenho feminino heterossexual e sexualizado. Assim, esses desempenhos sexualizados exigidos das mulheres em formas específicas de emprego remunerado podem complicar os significados do assédio sexual, chamando a atenção para a variação de experiência para as mulheres em todo o tipo de classe, sexualidade e raça.

Santos (2002) também informa que a caracterização do assédio sexual pode se dar através de comentários sexuais, tais como piadas, insinuações, propostas de atividades sexuais de qualquer espécie, tais como convites íntimos, passeios a lugares ermos, elogios ostensivos, ou com aproximações inoportunas, exibição de fotos, filmes sugerindo atividades sexuais, carícias ou, até mesmo, e o que é mais grave, com ameaças. Mas todas essas atitudes precisam ter a intenção de conseguir vantagem sexual, pois, caso isso não ocorra, não se configurará como assédio sexual.

Conforme mencionado por Hirigoyen (2014), outro ponto relevante à caracterização do assédio sexual é a constituição da relação que é imposta pelo assediador ao indivíduo assediado. $O$ assediador age de modo a pressionar o assediado para que aceite uma relação íntima que, em sua opinião, não seria aceita espontaneamente. Dessa forma, o objetivo maior é exercer dominação sobre a vítima, deixando-a em estado de sujeição psicológica para que seja manipulada.

Ademais, quando o assediador percebe que suas agressões estão sendo vistas como injustas, ele tende a usar táticas para diminuir a revolta. As táticas mais comuns são o encobrimento, onde o assediador age longe de testemunhas ou perto de testemunhas que percebem pouca responsabilização das suas ações por não ter muita interação com ele e com a vítima (Gettman \& Gelfand, 2007); a reinterpretação, em que o agressor nega ou alega má interpretação das suas ações, minimizando sua gravidade e culpando os outros; e a desvalorização da vítima, tal como por meio de rotulagem depreciativa (McDonald, 2010).

No que tange à vítima, as consequências do assédio sexual podem ser sequelas físicas e psicológicas em face da ofensa e da violência sofridas, que atinge sua liberdade sexual e sua dignidade como pessoa, atingindo também seu rendimento laboral. Dificilmente, encontra-se uma organização que não tenha ocorrido pelo menos um caso de assédio sexual. Também é difícil haver organização em que o tratamento utilizado não tenha envolvido o desligamento da vítima, ainda que "espontâneo" (FREITAS, 2001).

Os efeitos do assédio sexual na vítima incluem irritabilidade, ansiedade, tensão, depressão, deterioração das relações pessoais, hostilidade, insônia, fadiga e outros sintomas de estresse no trabalho. Megranahan (1989) afirma que as pessoas que são assediadas sexualmente são muitas vezes as que são menos capazes de se proteger. Eles podem ser jovens, sem habilidades interpessoais, tímidos e inibidos. As pessoas nessas categorias podem já ter baixa autoestima e o assédio sexual pode inibir ainda mais sua capacidade de desenvolver autoconfiança. Desse modo, as ocorrências de situações de assédio sexual trazem consequências que podem afetar o sujeito de forma, até mesmo, irreversível.

Houle et al. (2011) apontam para a longevidade desses efeitos, pois os alvos de assédio continuam a relatar sintomas depressivos quase uma década depois. O mesmo estudo liga o assédio sexual a outros aspectos da saúde mental, incluindo raiva e dúvida, o que provavelmente influenciará as futuras experiências de emprego das vítimas.

Ademais, o assédio sexual pode reduzir a moral e impor custos consideráveis aos empregadores em termos de eficiência, aumento de empregados doentes e, finalmente, perda de empregados experientes (FORSTER, 1992).

Mas Firestone e Harris (2003) observaram em seus estudos que aqueles responsáveis por solucionar os casos de assédio sexual em determinada organização tendem a preferir culpabilizações em nível individual ao invés de 
aceitar a responsabilidade organizacional.

Frente a esse contexto, o grupo formado por jovens trabalhadores, que estão em período de formação de identidade, tanto pessoal quanto laboral (PAIVA et al., 2013), merece especial atenção em relação ao esclarecimento dessa realidade. Assim, características desse grupo serão abordadas no tópico seguinte.

\subsection{Jovens Trabalhadores}

A juventude consiste em uma categoria sociológica que pode ser entendida como uma fase de transição entre a infância e a vida adulta (MESQUITA et al., 2012), envolvendo um grupo com "características e necessidades próprias, compartilhadas entre si e distintas das de outros grupos na sociedade" (UNFPA, 2010, p. 15). Tal grupo possui diversas idiossincrasias e ambiguidades, sendo os jovens, por vezes, considerados crianças e, outras vezes, considerados adultos (UNFPA, 2010).

Alguns autores, como Abramo (2005), Velho e Duarte (2010) e Veriguine, Basso e Soares (2014), consideram não ser possível pensar a juventude em sentido homogêneo e singular, uma vez que existem na realidade "juventudes" que envolvem grupos heterogêneos, com diversidades regionais, culturais, sociais e educacionais a serem consideradas (MESQUITA et al., 2012). Apesar de ter por base marcos etários e biológicos, a definição da população jovem é indissociável do seu contexto sociocultural, político e econômico (UNFPA, 2010).

Ser jovem, portanto, trata-se de uma fase delicada na qual surgem diversos questionamentos e necessidades de realizar escolhas e em que ocorre "aquisição das habilidades sociais, atribuições de deveres e responsabilidades e afirmação da identidade" (UNFPA, 2010, p. 15). As escolhas realizadas nessa fase de vida têm forte influência no futuro, como fator de ampliação ou limitação da vida adulta.

Nesse sentido, os jovens estão em busca de autonomia e liberdade, mas ainda não desenvolveram espírito crítico suficiente para tomadas de decisões assertivas. Este fato, propicia ao jovem maior suscetibilidade a se deixar levar por um discurso de transgressão ou de arregimentação por parte de um colega de trabalho manipulador, por exemplo (HIRIGOYEN, 2014).

Segundo definição da Organização das Nações Unidas (ONU), a juventude abarca as pessoas na faixa etária de 15 a 24 anos, podendo alcançar o patamar de 1,4 bilhão da população mundial até o ano de 2025 (UNFPA, 2010). Essa parcela representativa da população é marcada por peculiaridades, impacta e é impactada pelo contexto em que vive e se desenvolve (MESQUITA et al., 2012), sendo o mercado de trabalho um locus em que muitas dessas consequências podem ser notadas e devem se constituir alvos de reflexão.

Os jovens sofrem pressões, inclusive de si mesmos, para ingressar no mercado de trabalho, tornarem-se trabalhadores e descobrirem aquilo com o que se identificam, dando um "rumo" à vida. Mesmo com a flexibilidade do mercado e a maior abertura de possibilidades profissionais, "os jovens continuam a ser preparados/objetivados para se tornarem trabalhadores assalariados" (WICKERT, 2006, p. 259), em especial na sociedade brasileira, em que ser um "trabalhador" é um valor básico e distingue o "cidadão" do "marginal" (VERIGUINE et al., 2014). No entanto, existem determinados grupos ocupacionais e certos espaços de trabalho que contribuem para a invisibilidade de alguns conjuntos de trabalhadores, como é o caso dos mais jovens. É nesse momento de descoberta e de formação da identidade, que a organização se configura como "um importante espaço de socialização, aprendizado e discussão das responsabilidades e modos de agir e de pensar na vida adulta, além de ser o local no qual aprendem muitas das estratégias que irão utilizar no futuro, enquanto trabalhadores" (OLIVEIRA, 2011, p. 91), o que inclui o lidar com agressões e violências de toda ordem.

As taxas de desemprego são mais altas entre essa parcela da população (REIS, 2015), comparativamente aos adultos mais experientes, sendo mais expressivas entre os jovens que se encontram entre 15 e 17 anos (CORSEUIL; FRANCA, 2015). Além disso, pesquisas demonstram que os jovens trabalhadores normalmente enfrentam condições laborais ruins, trabalham em ocupações pouco qualificadas, recebem baixa remuneração e enfrentam jornadas de trabalho semanais superiores ao que seria adequado pela sua faixa etária (UNFPA, 2010; SILVA, 2015). De acordo com a Organização Internacional do Trabalho (ILO, 2016), existe maior incidência de pobreza no trabalho entre os jovens que entre os adultos, sendo que " $37,7 \%$ dos jovens trabalhadores estão vivendo em extrema ou moderada pobreza em 2016 , contra $26 \%$ dos adultos que trabalham".

Considerando o contexto do Brasil, os jovens representam cerca de um terço da população total do país, constituindo uma parcela significativa para o seu desenvolvimento (UNFPA, 2010). A partir de meados dos anos 2000, o Brasil vem atingindo taxas de desemprego menores, aumento da renda e maior formalização do mercado de trabalho, tanto no que tange aos jovens quanto a população em geral. Entretanto, ainda existem grandes desafios para os jovens nessas áreas (VENTURI e TORINI, 2014) e essas dificuldades vêm ganhando destaque na mídia e nos estudos brasileiros, uma vez que "trata-se de um problema social que repercute nos modos de ser de uma geração" (WICKERT, 2006, p. 268). 
As dificuldades na busca do primeiro emprego são ainda mais acentuadas quando se trata de trabalhos considerados de melhor qualidade (REIS, 2015). Os impasses da inserção profissional dos jovens em busca do primeiro emprego podem afetar os processos de filiação social dos mesmos, além de gerar impactos nos seus modos de subjetivação por meio do sofrimento oriundo do refreamento da vontade de tornarem-se sujeitos de suas próprias ações (WICKERT, 2006).

Dessa forma, o contexto de trabalho dos jovens pode ser considerado precário (POCHMANN, 1998; LOUGHLIN, LANG, 2005; PAIVA et al., 2013; REIS, 2015), permeado por instabilidade e rotatividade, sendo esta considerada a principal determinante do desemprego de jovens trabalhadores, que "encontram-se à deriva profissional e agarram-se a quaisquer possibilidades de inserção" (WICKERT, 2006, p. 269).

Frente às desigualdades nas condições laborais dos jovens em relação à inserção, remuneração, rotatividade, instabilidade e informalidade, e considerando, ainda, as idiossincrasias dessa fase da vida e a influência de fatores como gênero, renda familiar, nível educacional e localidade, os jovens trabalhadores podem se tornar mais propensos a sofrer casos de assédio, seja moral ou sexual. Isso aponta para a necessidade de políticas públicas e estudos que contemplem suas especificidades e contribuam em quantidade e qualidade para o conhecimento de temas como o assédio - moral e sexual - e para as oportunidades oferecidas à juventude. Ações nesse sentido contribuem para a sociedade como um todo e, em especial, influenciando "o desenvolvimento sustentável e equitativo da população brasileira" e dando aos jovens "condições para o enfrentamento e resolução dos problemas do dia a dia" (UNFPA, 2010, p. 55).

Buscando desnudar essa realidade que pode ser caracterizada como "espinhosa", mas de extrema relevância pessoal, organizacional e institucional -, a seção seguinte detalha a metodologia utilizada no desenvolvimento do presente estudo, que vincula a temática de assédio sexual ao público dos jovens trabalhadores.

\section{Metodologia}

A pesquisa empírica empreendida para o estudo apresentado nesse artigo utilizou abordagem qualitativa para alcançar o objetivo proposto. Essa abordagem pode ser entendida como:

Um processo de investigação e entendimento baseado em tradições de investigação metodológicas que exploram o problema humano e social. O pesquisador constrói um quadro complexo e holístico, analisa palavras, reporta detalhadamente as visões de informantes e conduz o estudo em um campo natural (CRESWELL, 1998, p. 15).

Seguindo essa concepção, o ato de analisar um determinado contexto abarca não somente as informações passadas de imediato pelos sujeitos informantes, mas, também, busca o aprofundamento da realidade posta em estudo, de modo a considerar detalhes ou pormenores das situações. Conforme afirmam Denzin e Lincoln (2007), a pesquisa qualitativa é, em si mesma, um campo de investigação, pois atravessa disciplinas, campos e temas. Assim, este método foi o desenvolvido, servindo-se de conceitos nos campos da Administração e do Direito.

Quanto aos fins, esta pesquisa se classifica como descritiva. Para Triviños (1987), este tipo de estudo permite descrever fatos e fenômenos de determinada realidade com acuidade científica, sendo ele adequado para se conhecer determinado grupo, suas características, valores e problemas. Nesse contexto, segundo Cervo e Bervian (2002, p. 66), “[...] a pesquisa descritiva observa, registra, analisa e correlaciona fatos ou fenômenos (variáveis) sem manipulá-los”.

Quanto aos meios, trata-se de uma pesquisa de campo, desenvolvida nos moldes de um estudo de caso. Este tipo de estudo é um meio de atingir diferentes propósitos, explorando exaustivamente e em profundidade um ou poucos objetos, de forma a conhecê-los de forma ampla e detalhada (VERGARA, 2006). Nesse sentido, destaca-se que os jovens da Associação Alfa são um caso particular de trabalhadores nessa faixa etária, pois se encontram em situação de vulnerabilidade de variadas ordens e recebem um treinamento profissionalizante que visa inseri-los e incluí-los no mercado de trabalho. Desse modo, foram feitas entrevistas com profissionais da Associação Alfa buscando um estudo aprofundado da percepção do fenômeno, no sentido de compreender e analisar o assédio moral.

A unidade de análise deste estudo foi a Associação Alfa, organização sem fins lucrativos que possui unidades em todo o território brasileiro e atua na capacitação de jovens para a entrada e inclusão dos mesmos no mercado de trabalho, direcionando-os a empresas parceiras de diversos segmentos, usualmente de grande porte. Foi adotado um nome fíctício para mencionar a associação neste estudo, tendo em vista que foi previamente pactuado o sigilo quanto à sua identificação. Focalizou-se uma unidade de Belo Horizonte (MG), considerando o critério de acessibilidade (VERGARA, 2006), concretizado na autorização formal da gerência geral; e intencionalidade (VERGARA, 2006), tendo em vista o acesso a informantes que convivem diariamente com os jovens. Vale ressaltar que, inicialmente, tentou-se o contato direto com os jovens trabalhadores para atingir o 
objetivo da pesquisa, entretanto, não se obteve êxito no retorno da Associação Alfa, visto que esta negou terminantemente qualquer contato com os jovens, mencionando ser uma forma de exposição destes profissionais. A partir deste retorno, foi impossível não fazer interpretações sobre as intenções da instituição ao promover o silêncio destes jovens profissionais, ao invés de estimular e dar voz a estes entrantes do mercado de trabalho. Após algumas negociações, a instituição autorizou o acesso aos profissionais que assistem os jovens no dia a dia de trabalho. Aceitou-se esse acesso por entender-se ser uma oportunidade de ouvir os jovens de forma indireta. Essa leitura que estes profissionais fazem da realidade dos jovens assistidos e a atuação direta que estes profissionais exercem sobre eles podem ser uma forma de busca da transformação de realidades pontuais que expressem algum problema organizacional.

Após o aceite de participação da pesquisa, os profissionais que trabalham na unidade abordada caracterizaram-se como os informantes dessa pesquisa e, portanto, constituíram-se como a unidade de observação deste estudo, dando-se início à coleta de dados. Esta utilizou como instrumento a entrevista com roteiro semiestruturado, que foi aplicada a 21 informantes da associação, de forma individual, sendo 14 instrutores, 3 analistas de acompanhamento, 1 assistente social, 1 psicólogo e 2 coordenadores. O enfoque inicial da pesquisa constituía em abordar o assédio moral, entretanto, alguns desses profissionais relataram situações de assédio sexual vivenciadas pelos jovens trabalhadores, aspecto específico sobre o qual este estudo se debruça.

As entrevistas foram gravadas e transcritas na íntegra, e os dados obtidos foram submetidos à Análise de Conteúdo (AC), com a finalidade de interpretar as realidades vivenciadas pelos jovens trabalhadores quanto ao tema central desse estudo - o assédio sexual - por meio da linguagem. Aqui, compreende-se linguagem não somente como uma forma de expressão, mas também de produção e reprodução do mundo social (GIALDINO, 2009). De forma a facilitar a compreensão e interpretação dos dados, eles foram categorizados em relação ao entendimento e abrangência do conceito de assédio sexual, sua ocorrência nas organizações, políticas e práticas para sua prevenção e as consequências desse assédio para as vítimas. A apresentação e análise dos resultados são descritas no tópico a seguir.

\section{Análise Dos Resultados}

Conforme já exposto, os dados obtidos sobre o assédio sexual com jovens trabalhadores surgiram a partir de uma pesquisa com foco em assédio moral realizada com profissionais que assistem este público em uma associação de formação profissional exclusiva de jovens trabalhadores, em uma de suas unidades na cidade de Belo Horizonte (MG). As entrevistas foram conduzidas a partir de um roteiro semiestruturado, dividido em duas partes. A primeira parte teve o intuito de coletar informações socioeconômicas dos entrevistados, como informações sobre o perfil do entrevistado (sexo, idade, estado civil, escolaridade), informações sobre o trabalho em si, como a função desempenhada e a jornada de trabalho, e informações sobre a família do entrevistado. Já a segunda parte focou no assédio moral em si, com perguntas diretas e objetivas, abordando conteúdos explícita e implicitamente. Ela foi subdividida em itens sobre o ambiente de trabalho dos jovens; a compreensão sobre o assédio; o assédio moral de jovens no trabalho; e a extensão e prevenção do assédio. A tabela 1 apresenta o perfil dos entrevistados:

Tabela 1: Perfil dos entrevistados.

\begin{tabular}{|c|c|c|c|}
\hline Dados pessoais & Categorias & $\begin{array}{c}\text { Número de } \\
\text { Respondentes }\end{array}$ & $\begin{array}{c}\% \text { de } \\
\text { Respondentes }\end{array}$ \\
\hline \multirow[t]{2}{*}{ Sexo } & Feminino & 17 & 80,95 \\
\hline & Masculino & 4 & 19,05 \\
\hline \multirow[t]{4}{*}{ Idade } & Entre 20 e 30 anos & 6 & 28,5 \\
\hline & Entre 31 e 40 anos & 7 & 33,33 \\
\hline & Entre 41 e 50 anos & 4 & 19,05 \\
\hline & Não respondeu & 4 & 19,05 \\
\hline \multirow[t]{6}{*}{ Estado civil } & Solteiro(a) & 11 & 52,38 \\
\hline & Casado(a) & 9 & 42,85 \\
\hline & União Estável & 0 & 0,0 \\
\hline & Viúvo(a) & 0 & 0,0 \\
\hline & Divorciado(a)/ Separado(a) & 1 & 4,77 \\
\hline & Outro & 0 & 0,0 \\
\hline \multirow[t]{4}{*}{ Escolaridade } & Ensino superior incompleto & 0 & 0,0 \\
\hline & Ensino superior incompleto & 4 & 19,05 \\
\hline & Pós-graduação incompleta & 5 & 23,80 \\
\hline & Pós-graduação completa & 12 & 57,15 \\
\hline \multirow[t]{2}{*}{ Cargo atual } & Analista de acompanhamento & 3 & 14,30 \\
\hline & Coordenador(a) & 2 & 9,52 \\
\hline
\end{tabular}




\begin{tabular}{cccc}
\hline Instrutor(a) & $\mathbf{1 4}$ & $\mathbf{6 6 , 6 6}$ \\
\cline { 2 - 4 } & Psicólogo(a) & 1 & 4,76 \\
\hline Assistente social & 1 & 4,76 \\
\hline
\end{tabular}

Fonte: Dados da pesquisa.

No decorrer das entrevistas, evidenciou-se que, além do assédio moral, também ocorrem situações de assédio sexual sofridas pelos jovens trabalhadores assistidos na associação. Esta percepção se concretizou em dois momentos, especificamente: quando os profissionais entrevistados da Associação Alfa responderam à pergunta sobre a sua compreensão do que é o assédio moral e o que os jovens trabalhadores entendem por assédio moral (na percepção dos entrevistados); e a pergunta que indaga se os entrevistados já haviam sido informados de algum caso de assédio sofrido pelos jovens trabalhadores. Em ambos os momentos, foram mencionadas situações de assédio sexual no cotidiano laboral de jovens trabalhadores e, a partir desse contexto, a entrevista seguiu com questionamentos tanto sobre o assédio moral, como sobre o assédio sexual.

Inicialmente, foi percebida nas entrevistas a dificuldade dos profissionais em definir assédio, e saber distinguir assédio moral de assédio sexual.

Ah é uma, uma coisa muito complexa assim pra gente poder explicar, falar assim, um conceito básico, acho que uma dificuldade que muitas pessoas têm, às vezes é saber separar o assédio moral do assédio sexual, e isso é uma, é, até o, os próprios jovens, têm uma certa dificuldade. (E17)

Então, é muito difícil você também entender o assédio. Não é uma questão que é trabalhada, discutida. Eu nunca, em lugar nenhum, já me falaram sobre assédio. Na minha formação não foi falado. (E21)

Os entrevistados destacaram que existe dificuldade também por parte dos jovens em saber ao certo o que pode ser considerado assédio e a diferença entre assédio moral e assédio sexual. Quando os profissionais da Associação Alfa tomaram ciência de relatos de assédio moral e sexual, os jovens nem mesmo utilizaram a palavra assédio para caracterizar as situações vivenciadas.

O que é o, às vezes eu percebo que o jovem não tem essa diferenciação, um caso de uma jovem, ela chegou e falou assim, que ela tava sofrendo assédio, assédio na empresa. Aí a gente foi conversar com a jovem que, o que tava acontecendo: "o meu gestor fala que eu, falou pra um, colega de trabalho que eu sou bonita". (E17)

Eu... Na minha percepção é que o jovem não tem clareza exatamente do que que é um assédio moral, o que é um assédio sexual, e o que que é uma questão assim, propriamente do dia a dia. (E17)

É... não usou a palavra assédio, né? Falou que tentou beijá-la, que tentou... que fez comentários inadequados, isso sim. (E18)

A dificuldade percebida em caracterizar os termos assédio moral ou assédio sexual dos entrevistados e dos próprios jovens trabalhadores revela o quanto o assunto não é discutido no cotidiano de ambos os grupos de trabalhadores, sendo ainda mal compreendido por eles. Conforme referenciado, há uma definição estabelecida para assédio sexual em virtude de lei que o prevê, o Código Penal Brasileiro (1940), em seu artigo 216-A, além de caracterizações de conceitos.

Contudo, tal fenômeno não é algo tão distante no cotidiano dos jovens, merecendo destaque o fato de que 5 dos profissionais entrevistados responderam que foram informados sobre a ocorrência de assédio sexual contra os jovens, como pode ser visto nos relatos a seguir:

Ah esse que chegou, que eu tive conhecimento de assédio, foi um recente agora a gente tá até trabalhando inclusive em cima dele também... Foram 3 casos. Então assim, recentemente mesmo a gente atendeu uma mãe que chegou aqui e veio comentar que, a filha, no local de trabalho dela ela, foi assediada, assediada por um colega né? Que trabalha numa sala em frente a sala que ela trabalha, tava sozinha e aí ele chegou, pediu pra poder é, perguntou se ela sentindo frio, se queria que aquecesse ela e ela falou que não, que não queria né? E aí ele segurou no braço e, perguntou pra ela "então me dá um beijo aqui." Gerou, é um caso que a gente tá acompanhando ainda né? Mas, a gente não sabe ainda como é que vai ser as providências. A gente já, conversou com a mãe né? Vai ser feita uma visita na empresa, e os gestores todos estão dando o maior suporte à jovem, tá? O que a mãe falou pra nós é que eles estão com muito cuidado com ela, ela não fica mais sozinha na sala, horário de almoço ela sai junto com todo mundo, ele não deixam ela ficar sozinha, sabe? A mãe também tá, com cuidado né? Orientou na hora de chegar na empresa, na hora de ir embora né? Tá sempre acompanhada... (E19)

Um caso que eu peguei e, no final, não fui eu que tratei o caso, foi de uma jovem que sofreu assédio dentro da empresa, o gestor tentou agarrar a jovem, e depois de muito tempo que ela chegou pra relatar isso, ela relatou pro instrutor em sala de aula, no mesmo dia a gente já começou com a orientação... A, a jovem não chegou nem a comentar com a família né? Nem com ninguém na empresa. [...] Primeira coisa foi tirar o jovem de dentro da empresa, quando já é uma coisa que é constatada, igual, a jovem relatou que o jovem, que o gestor tentou agarrar ela, dar um beijo nela 
dentro da empresa. Quando a jovem já chegou a relatar, primeiro passo foi tirar a jovem de dentro da empresa. (E17)

Eu fui atender uma menina que... na verdade atendi a mãe, que a menina tava passando por uma situação, assim... infelizmente, né? É raro acontecer mas acontece. Mas ela contou e foi uma situação desagradável, assim, né? Não era o gestor dela, era uma pessoa que trabalhava na mesma empresa. Ele trabalhava na empresa. Tinha acesso ao setor onde a menina tava mas não tinha ligação com o trabalho dela não. Falou que tentou beijá-la, que tentou... que fez comentários inadequados. (E18)

E uma outra situação no banco, foi um segurança. Então não era o gestor da menina. Ela trabalhava lá no caixa, no autoatendimento, e direto, sempre aquele segurança que fica na porta falava alguma coisa indiretamente pra ela. Ah, que ela é bonita, que no outro dia a roupa ta bonita... ia com vário elogios ali, até tentar conseguir alguma coisa.[...] A situação da menina, foram... várias as situações. O segurança tava ali assediando ela direto. (E21)

Já aconteceu situação de... de assédio moral no sentido de mais assédio sexual mesmo. É... que no caso de jovem, de mulher né? E ai que o funcionário, né? De ter situações de trazer, às vezes, brincando... brincadeirinhas, de comentar da vestimenta, né? De ficar sempre naqueles elogios, né? Que chega a incomodar... né? O jovem... então, né? Isso, já. (E16)

Nos casos narrados anteriormente, é possível perceber o assédio sexual, já que os agentes utilizaram da sua condição de superior hierárquico (E17) ou da sua superioridade em termos do poder de mando que possuem na relação de trabalho (E16, E18, E19, E21) para assediarem os jovens envolvidos, como enuncia a literatura do tema (GRECO, 2012).

Ademais, percebeu-se que todos os casos de assédio sexual narrados ocorreram contra mulheres. Esse fato corrobora os dados da Organização Internacional do Trabalho (OIT, 2012) que afirma que 77\% das mulheres já sofreram algum tipo de assédio sexual e que $52 \%$ das mulheres economicamente ativas já foram assediadas sexualmente. A OIT (2012) também informa que o assédio sexual é o segundo maior problema enfrentado pelas mulheres no ambiente de trabalho, ficando atrás somente dos baixos salários.

Fitzgerald et al., em 1988, já identificava o assédio sexual como uma das mais prejudiciais barreiras ao sucesso profissional e à satisfação das mulheres.

A respeito da forma com que casos como esses são tratados na Associação Alfa, percebeu-se por meio dos relatos que, quando os fatos chegam ao conhecimento dos profissionais da instituição, geralmente há transferência ou desligamento do jovem da empresa, como pontuado por Freitas (2001), e evidenciado nos trechos abaixo.

Um desligamento, uma transferência de empresa, teve caso aqui também mais antigo que eu me lembro agora, também da questão de assédio sexual e que a gente conseguiu uma... porque assim, quando o jovem assina o contrato, né? Ele não pode ser aprendiz de novo. E nesse caso, como aconteceu uma situação assim, que não foi, que a gente precisou que o contrato fosse encerrado pra a menina sair da empresa, pra protege-la, a gente conseguiu uma autorização do Ministério do Trabalho pra que ela fosse reconduzida para uma outra empresa. (E18)

Primeira coisa é tirar o jovem de dentro da empresa, quando já é uma coisa assim, que é constatada, igual, a jovem relatou que o jovem, que o gestor tentou agarrar ela, dar um beijo nela dentro da empresa. Quando a jovem já chegou a relatar, primeiro passo foi tirar a jovem de dentro da empresa. (E17)

Dessa forma, pelos trechos acima, é possível perceber que, quando ocorre alguma prática de assédio sexual nessas organizações, uma das consequências diretas sobre os jovens profissionais é o seu desligamento ou transferência de empresa, como enunciado pelos estudiosos do tema (FREITAS, 2001), como forma de "proteger" o sujeitovítima. Tal jovem vítima, que já passou por uma situação constrangedora dentro da organização e que sofreu o abuso, é que é transferido ou desligado da organização. No entanto, nada foi citado pelos entrevistados sobre o que acontece com o agressor nesses casos, demonstrando que, muitas vezes, o assédio fica impune dentro das organizações. Tal fato pode contribuir para que as vítimas não denunciem quem pratica o abuso, uma vez que, se denunciarem, elas têm seus empregos e benefícios ameaçados, o que é referenciado pelos estudiosos do tema (SANTOS, 2002), sendo justificados pela suposição de "proteção", e também porque não veem ocorrer medidas punitivas com o agressor, como são aplicadas com elas, segundo seu entendimento.

Em algumas das entrevistas, foi possível notar que os profissionais da Associação Alfa acreditam que cabe ao jovem se prevenir do assédio sexual, como se o jovem fosse responsável por dar abertura de alguma forma para ser assediado no ambiente de trabalho ou tivesse uma parcela de culpa em casos de assédio sexual, devido a comportamentos de maior intimidade com os colegas de trabalho e uso de roupas inadequadas. Essa inversão da culpabilidade do assédio sexual do assediador para o assediado (vítima) foi mencionado por Hirigoyen (2014) e também são relatados nos trechos das entrevistas a seguir:

Sobre, de uma maneira geral, a gente sempre conversa muito com o jovem, né, sobre essas questões de, de, de, de não dar motivo pra que aconteça essa situação, também, né, principalmente de assédio, né, porque às vezes pode acontecer... assédio sexual no caso, né. Por exemplo, se a moça vai trabalhar com roupas inadequadas, né, e, e aí, né, no local de trabalho, né, que trabalha homem e mulher, né, então, assim, é não dar, não dar motivo. (E19) 
Que o assédio, a gente também tem que se prevenir do assédio. A gente não pode achar assim... o assédio ele vai acontecer. Tá, ele pode acontecer. Mas o que você pode fazer pra se prevenir? (...)

Que aí vai analisar os riscos, em que a vulnerabilidade aconteceu, né? Até isso é importante, né? Que as vezes o jovem está numa situação de assédio, justamente porque tá vulnerável em alguma situação. (...)

É como se fosse aquela questão do que é, como funciona, qual meu papel nisso... porque eu acredito que, quem sofre o assédio, a pessoa tem que também saber se resguardar, de não se expor, né? E isso é uma fase que até que pra eles está muito fácil de acontecer. Tá mais aflorado, eles tão com interesse de serem efetivado. A gente já viu caso no interior, por exemplo, da jovem mudar de agência, e aí ela tava indo com o gestor embora de carro. Então na época ela falou, que o gestor falou que podia ser contratada e acaba seduzida pela situação. Quando surge esse assunto eles têm interesse pra saber se tá acontecendo com eles ou não. E não, porque deixa eu me prevenir quanto a isso. Que o assédio, a gente também tem que se prevenir do assédio. (E21)

Dos fragmentos acima, chama-se atenção, primeiro, para uma afirmação: a de que o assédio vai ou pode acontecer nas organizações (E21). Essa declaração foi evidenciada porque demonstra que o assédio sexual é naturalizado para algumas pessoas como uma prática usual nas organizações. Sabe-se que o assédio sexual não é um fenômeno recente nas organizações (FREITAS, 2001) e, por ser tão recorrente, há, em alguns casos como no relatado por E21, uma banalização da sua prática dentro das empresas, silenciando a gravidade do ato e as consequências do abuso sexual para a vítima, daí sua inclusão no título deste artigo.

Além disso, é possível perceber, ainda, a prática da culpabilização da vítima pelo acometimento do assédio sexual, prática referenciada na literatura especializada do tema (HIRIGOYEN, 2014), que ocorre quando a vítima de um crime é considerada responsável pelo que aconteceu com ela. Culpar a vítima pelos atos sofridos é extremante sério, devendo ser visto com preocupação. Em algumas falas (E19 e E21), pôde-se perceber como a ideia de culpabilização mostra a prevalência de uma cultura não apenas machista na sociedade em que muitas vezes as próprias mulheres ainda são consideradas responsáveis pela violência sexual sofrida, seja por não se comportarem "adequadamente", seja por usarem roupas provocantes, mas também misógina, sendo a violência sofrida justificável.

Possivelmente, concepções como as expostas anteriormente funcionam como bloqueios para que o jovem expresse os constrangimentos e sofrimentos vivenciados no ambiente de trabalho. Além disso, os entrevistados relataram que existe medo por parte dos jovens de expor tais situações diante do receio de consequências como perder o emprego ou "manchar" sua imagem no mercado de trabalho, como relatado por Santos (2002) e descrito nos fragmentos a seguir.

É tipo “e eu reclamo, eu posso não estar mais com meu trabalho depois de reclamar”, né? (E1)

(...) então outra coisa com essa crise que estamos vivendo, ele tem medo de ser bloqueado no mercado de trabalho né, das empresa relacionar há aquele jovem é problema é né, tava em outra empresa, gerou um problema naquela outra empresa ele tem medo de comunicação entre empresas, de pedir uma referência daquele jovem naquela empresa, da pessoa falar ...O...ele é um ótimo jovem, mas teve um problema ai né, então ele tem esse medo de falar e de manchar a imagem dele em relação ao mercado de trabalho, né... (E7)

Olha, primeira coisa que surge é exatamente o medo. O medo de: "eu não vou ficar, não vou terminar o meu contrato", é, "eles vão me mandar embora a qualquer momento, o que que vão falar de mim no futuro". (E11)

Eles não querem perder o emprego, né? Então eles vão ficar ali, né? Vão ficar com aquela informação até que... aquilo, às vezes, venha mesmo talvez causar um nível de sofrimento e aí 'eu não aguento mais'. (E16)

De acordo com O'Reilly e Garrett (2017) as baixas taxas de notificação de assédio sexual e a ambiguidade dos comportamentos de assédio sexual podem ser teoricamente ligadas ao que Bourdieu (2000) denominava violência simbólica, bem como outras formas de dominação desconhecidas.

Além do receio do julgamento de terceiros e de perder o emprego, também foi relatado que os jovens têm medo da exposição vinculada às possíveis denúncias de assédio sexual:

(...) então ele não coloca a situação, as vezes ele esconde a situação pra ele não ser exposto, porque ele sabe se ele for exposto vai ter um processo, ai não vai ser uma coisa que vai terminar de um dia pro outro. (E7)

Quando questionados sobre possíveis reflexos do assédio sexual, os entrevistados destacaram desmotivação e consequências psicológicas, como pontuado também por Freitas (2001) no tocante as consequências do assédio sexual nas organizações para quem é assediado.

(...) desmotivação. É a primeira coisa. Porque ainda mais que tá no inicio de carreira profissional, ele... ele vai ficar com um estigma muito forte na... na cabeça dele... porque será que trabalho é... essa situação x que ele tá vivendo, né? Eles chegam pra gente e perguntam assim... oh, tutor, é... mas todo lugar funciona dessa forma? (E1) 
(...) Eu acho que pode afetar diretamente a autoestima, autoconfiança, é, que interfere no desenvolvimento e no crescimento profissional... pode dar um bloqueio, mesmo. Não querer trabalhar ou ficar dentro de casa, levando até a uma depressão dependendo do... do, do assédio e da exposição. (E4)

Hirigoyen (2006) explica que o indivíduo assediado, muitas vezes, busca respostas para o que lhe ocorre e somente encontra desgosto e sentimento de inferioridade, dentre outros sentimentos que podem culminar, inclusive, para um quadro de depressão.

Nesse sentido, Schmidt (2002) exemplifica vários efeitos do assédio moral como a coisificação da pessoa, o sentimento de pouca utilidade e fracasso, a diminuição da produtividade, o aumento do absenteísmo, a demissão, o enfraquecimento da saúde e a tensão nos relacionamentos afetivos, e a falta de solução, que acabam levando a vítima, já sem esperanças, a não sentir mais vontade de viver.

Salvador (2002) apresenta os efeitos da violência sexual como um processo destruidor que pode conduzir a vítima a uma incapacidade permanente e mesmo à morte: o chamado bullicídio. A agressão tende a desencadear ansiedade, e a vítima se coloca em atitude defensiva (hipervigilância) por ter a sensação de ameaça e, além disso, sentimentos de fracasso e impotência tornam-se frequentes.

Alguns entrevistados relataram também situações em que eles próprios foram alvo de assédio moral e de assédio sexual, ao longo de sua vida profissional. Nesses momentos das entrevistas, a dor e o sofrimento vieram à tona, mostrando, mais uma vez, a importância de se tratar dessas questões também com os jovens com os quais tais profissionais lidam no seu cotidiano.

Então, eu por exemplo sofri duas vezes assédio. Uma na empresa que foi assédio é moral... o primeiro que eu passei foi assédio sexual, né? A pessoa me agrediu e queria tirar minha roupa a força. Queria né? À força. E esse... então isso foi muito claro. Nesse dia, na hora que essa pessoa me agrediu e rasgou minha roupa, eu registrei um boletim de ocorrência e chamei a polícia, no meu local de trabalho. Eu tava no meu local de trabalho, eu chamei a policia, e registrei um boletim de ocorrência e levei à direção. A direção entendeu que aquilo não era correto e desligou a pessoa. (E21)

Contudo, segundo os entrevistados, não existem programas, políticas e práticas formais realizadas pela Associação Alfa que abordem diretamente tanto o assédio moral quanto o assédio sexual. Apenas em 2014, foi feita uma campanha sobre assédio sexual realizada antes da Copa do Mundo no Brasil, fruto de uma política pública mais ampla, em função dos avanços turísticos derivados de tal evento esportivo no cenário nacional e internacional.

\begin{abstract}
Não, nunca, nunca teve, é... pelo tempo que eu estou aqui não me recordo. Eu já, já fiz um projeto, em 2014 que não, né, não tem a ver com, diretamente com assédio moral, ele foca mais o assédio, né, sexual e tudo, que foi na época da copa do mundo que eu trabalhei tanto o, o assédio sexual com o tráfico de pessoas. Trabalhei com essa conscientização porque o jovem é muito iludido, as fronteiras abertas, turistas, né, e o brasileiro tem uma cultura ridícula que é de quase estender um tapete vermelho pra quem mora fora, a gente nem sabe a procedência dessa pessoa, mas a gente, né, tem essa, essa questão e também porque o Brasil tem essa fama. Então eu trabalhei uma período de Maio e Junho todo aplicando projeto, falando pra eles desse, desse... pra tentar prevenir, né, a integridade, preservar integridade, mas... (E4)
\end{abstract}

Tá num tópico, que o instrutor conversa, fala um pouco sobre isso. Mas a gente não tem uma forma de atendimento, um espaço pra falar isso abertamente, não. (E21)

Chama a atenção o fato de que, mesmo existindo casos de assédio sexual, mesmo havendo consciência que os jovens muitas vezes nem mesmo sabem distinguir o que é assédio sexual e o que não é, e, mesmo diante do fato dos jovens se encontrarem em situação de vulnerabilidade, não existem ações da Associação Alfa voltadas para o tema, nem individuais por parte de instrutores e outros profissionais da instituição. Apesar disso, os entrevistados afirmaram que há interesse dos jovens pelo assunto do assédio sexual.

Sim. É...qualquer que seja, né, o tipo de assédio, eles se interessam. Eu percebo isso, que eles querem entender mais, né, sobre, sobre essa situação e eles começam a relatar, dentro daquilo ali, as coisas que já aconteceram. Às vezes, não aqui, né, diretamente, não dentro da empresa diretamente, mas aí eles começam a se empolgar um pouco mais e a contar pra gente: "ah, já aconteceu comigo" ou "já aconteceu com alguém, né, próximo de mim". e aí eles tem essa, essa questão de querer buscar mais (...). (E5)

Há busca constante por informação. Eles buscam constantemente o que que, sobre o que que é, é... o assédio mais comentado é o sexual, é o que a mídia mais joga em cima deles. (E6)

A esse respeito, Nunes e Tolfo (2013) informam que é preciso que haja, dentro das organizações, o desenvolvimento de políticas antiassédio, medidas de divulgação, prevenção e intervenção. É preciso descongelar padrões de comportamento e reaprender novos princípios e práticas. O fato é que as organizações precisam efetivamente desenvolver e aplicar ações que objetivem a eliminação ou redução dos riscos que envolvem a incidência de violências no ambiente do trabalho, promovendo, desse modo, um clima e ambiente saudável aos seus trabalhadores. 
Por fim, houve reconhecimento por alguns entrevistados acerca da importância da pesquisa, destacando que é um assunto velado, mas que precisa ser abordado, uma vez que o assédio sexual ainda é um fenômeno recorrente nas organizações, como informa a literatura do tema (FREITAS, 2001).

(...) a população não lê de um modo geral mas, coisas polêmicas chamam atenção. Isso é polêmico e não tá na, não tá na boca do povo infelizmente, porque se estivesse a gente talvez teria menos incidência, né? Não necessariamente, mas pelo menos a gente teria mais denúncia. (E12)

Diante desses achados, as seguintes considerações finais foram traçadas.

\section{Conclusão}

Objetivou-se no presente trabalho analisar como são percebidas as situações de assédio sexual vivenciadas por jovens trabalhadores sob a perspectiva de profissionais da Associação Alfa. O objetivo proposto foi atingido uma vez que foi possível compreender as situações de assédio sexual sofridas por jovens trabalhadores no seu ambiente de trabalho percebidas e narradas pelos referidos profissionais. Nos casos relatados, os agentes (profissionais que trabalhavam com jovens nas suas organizações) utilizaram da sua condição de superior hierárquico ou da sua superioridade em termos do poder de mando que possuem na relação de trabalho para assediarem os jovens envolvidos. Destacam-se relatos nas entrevistas sobre a prática de assédio sexual contra jovens trabalhadoras, evidenciando um viés de gênero. Esses dados corroboram estatísticas internacionais que demonstram que a maioria das vítimas do assédio sexual são mulheres.

Percebeu-se que existe um medo por parte dos jovens de expor tais situações por receio de perder o emprego ou "manchar" sua imagem no mercado de trabalho, de "sujar" a carteira de trabalho pela finalização precoce do vínculo de trabalho. Também notou-se que os jovens assediados podem sofrer uma desmotivação no trabalho e/ou consequências psicológicas. Além disso, mesmo existindo casos de assédio sexual, e mesmo diante do fato de os jovens se encontrarem em situação de vulnerabilidade, não existem ações da Associação Alfa voltadas para o tema, seja para prevenção, seja para conscientização desses jovens, ou mesmo para desenvolvimento de estratégias de defesa ou resistência.

Ademais, ficou evidente pelas entrevistas que alguns profissionais da Associação Alfa percebem o assédio sexual como algo natural e corriqueiro nas organizações, algo banalizado, o que precisa ser revisto, diante do papel de formadores de opinião que exercem na associação, frente aos jovens.

Outro ponto importante de destacar é que, além de sofrer o assédio sexual, a vítima ainda é desligada ou transferida de organização, demonstrando que, muitas vezes, a culpa - e, no seu julgamento, a punição - recai sobre ela, e que suas consequências são muito mais ostensivas do que para o assediador, se é que eles são penalizados de alguma forma.

Portanto, é notória a necessidade de se debater tal temática nas organizações, de forma com que os trabalhadores compreendam não apenas o conceito de assédio sexual, mas desnaturalizem essa prática nas relações de trabalho e desconstruam a noção de que a vítima é culpada por ter sofrido a agressão.

Assim sendo, vê-se a necessidade de transpor medos ou receios de informar os jovens sobre assédio sexual ou qualquer outro tipo de situação que lhe seja prejudicial, pessoal e/ou profissionalmente. Também, não se deve aceitar que se banalize o sofrimento e a injustiça. Daí a necessidade de diálogo entre todas as instâncias envolvidas com esse público.

Por fim, uma limitação desta pesquisa foi justamente o veto da Associação Alfa de qualquer diálogo com os jovens trabalhadores a respeito do tema assédio, de forma a complementar os resultados encontrados. Para pesquisas posteriores, sugere-se avançar no tema central aqui exposto - o assédio sexual nas organizações -, dando voz principalmente a esses jovens trabalhadores, independentemente do porte ou setor das organizações em que eles trabalham, já que isso poderia ajudar na eliminação ou redução dos riscos que envolvem a incidência de violências contra esse público.

Assim sendo, políticas e práticas de gestão de pessoas podem ser revistas, a iniciar-se pelos processos de treinamento e desenvolvimento de pessoal, incluindo-se programas informativos e formativos quanto aos temas aqui trabalhados, já que os trabalhadores adultos ou mais experientes são os principais agentes do assédio e carecem de revisar, com urgência, suas relações interpessoais, focadamente suas práticas de poder, ainda mais considerando-se o público aqui abordado, dadas as consequências que tais relacionamentos podem acarretar na massa trabalhadora "do futuro", como as citadas pelos entrevistados. Os jovens, hoje parte de um grupo considerável "invisível” no mercado de trabalho, num futuro próximo irá ocupar postos de comando e a reprodução de tais práticas não é, definitivamente, um caminho saudável para as relações sócio-políticas nas organizações. 


\section{Referências}

ABRAMO, H. W. Condição juvenil no Brasil contemporâneo. In: ABRAMO, H. W.; BRANCO, P. P. M. Retratos da Juventude Brasileira. São Paulo: Instituto Cidadania, Editora Fundação Perseu Abramo, p. 417, 2005.

BARDIN, L. Análise de conteúdo. São Paulo: Editora 70, 2011.

BARROS, A. M. O assédio sexual no direito do trabalho comparado. Gênesis - Revista de Direito do Trabalho, v. 70, p. 503, 1998.

BOURDIEU, P. Pascalian Meditations. Cambridge: Polity Press, 2000.

BRASIL. Decreto Lei n ${ }^{\circ}$ 2.848, de 7 de dezembro de 1940. Código Penal Brasileiro. Diário Oficial da União. Brasília, 08 de dezembro de 1940.

BRUNNER, L. K.; DEVER, M. Work, Bodies and Boundaries: Talking Sexual Harassment in the New Economy. Gender, Work \& Organization, v. 21, p. 459-471, 2014.

CERVO, A, L.; BERVIAN, P. A. Metodologia científica. 5. ed. São Paulo: Pearson Prentice Hall, 2002.

CORSEUIL, C. H. L.; FRANCA, M. A. P. Inserção dos jovens no mercado de trabalho brasileiro: evolução e desigualdades no período 2006-2013. Organização Internacional do Trabalho. Brasília: OIT, 2015.

CRESWELL, J. W. Qualitative inquiry and research design: choosing among Five traditions. Thousand Oaks, California: Sage Publications, 1998.

DENZIN, N. K.; LINCOLN, Y. S. O planejamento da pesquisa qualitativa: teorias e abordagens. Porto Alegre: Bookman e Artmed, 2007.

DIAS, I. Violência contra as mulheres no trabalho: o caso do assédio sexual. Sociologia, Problemas e Práticas [online]. n.57, p.11-23, 2008.

FELKER, R. D. H. O dano moral, o assédio moral e o assédio sexual nas relações do trabalho. São Paulo: LTr, p. 221-259, 2006.

FIRESTONE, J. M.; HARRIS, R. J. Perceptions of Effectiveness of Responses to Sexual Harassment in the US Military, 1988 and 1995. Gender, Work and Organization, p. 42-64, 2003.

FITZGERALD, L. F. Sexual harassment: Violence against women in the workplace. American Psychologist, v. 48, n. 10, p. 1070-1076, 1993.

FITZGERALD, L. F.; SHULLMAN, S. L., BAILEY, N; RICHARDS, M; SWECKER, J; GOLD. Y. The incidence and dimensions of sexual harassment in academia and the workplace. Journal of Vocational Behavior, p. 152$175,1988$.

FORD, R. C.; MCLAUGHLIN, F. S. Sexual harassment at work. Business Horizons, v. 31, n. 6, p. 14-19, 1988. FORSTER, P. Sexual Harassment at Work. BMJ: British Medical Journal. p. 944-946, 1992.

FREITAS, M.E. Assédio moral e assédio sexual: faces do poder perverso nas organizações. Revista de Administração de Empresas, v. 41, n. 2, p. 8-19, 2001.

GETTMAN, H. J.; GELFAND, M. J. When the customer shouldn't be king: Antecedents and consequences of sexual harassment by clients and customers. Journal of Applied Psychology, v. 92, 7p. 57-770, 2007.

GIALDINO, I. V. Los fundamentos ontológicos y epistemológicos de la investigación cualitativa. Forum: Qualitative Social Research, Berlin, v. 10, n. 2, Art. 30, 2009.

GRECO, R. Curso de direito penal. $9^{\text {a }}$ ed. -. São Paulo: Impetus, 2012. Parte especial - Volume III.

HIGA, F. C. Assédio sexual no trabalho e discriminação de gênero: duas faces da mesma moeda?. Revista Direito GV, São Paulo, v. 12, n. 2, p. 484-515, 2016.

HIRIGOYEN, M. F. Assédio moral: a violência perversa no cotidiano. $14^{\text {a }}$ ed. Rio de Janeiro: Bertrand Brasil, 2014.

HOULE, J. N.; STAFF, J.; MORTIMER, J. T., UGGEN, C.; BLACKSTONE, A.The impact of sexual harassment on depressive symptoms during the early occupational career. Society and Mental Health, p. 89-105, 2011.

INTERNATIONAL LABOUR OFFICE. World Employment Social Outlook: Trends for Youth 2016. International Labour Organization. Geneva: ILO, 2016.

LOUGHLIN, C.; LANG, K. Young workers. In: BARLING, J.; KELlOWAY, E. K.; FRONE, M. R. (eds.), Handbook of work stress. Thousand Oaks: Sage, 2005. p. 405-430.

MCDONALD, P. Workplace sexual harassment 30 years on: a review of the literature. International Journal of Management Reviews, v.14, p. 1-17, 2012.

MEGRANAHAN, M. Counselling: a practical guide for employers. London: Institute of Personnel Management, p.116-27, 1989.

MESQUITA, M. R.; JÚNIOR, G. M.; SIMÕES, A. A. A Juventude brasileira e a educação. Revista Juventude.Br, v. 6, p. 38-46, 2012.

NUNES, T. S.; TOLFO, S. R.; ESPINOSA, L. M. C. Assédio moral no trabalho: a compreensão dos trabalhadores sobre a violência. Revista de Gestão e Secretariado, v. 9, n. 2, p. 205-219, 2018.

NUNES, T. S.; TOLFO, S. R.; NUNES, L. S. Assédio moral em universidade: a violência identificada por servidores docentes e técnico-administrativos. Revista Organizações em Contexto, v. 9, n. 18, p. 25-61, 2013. 
OIT - ORGANIZAÇÃO INTERNACIONAL DO TRABALHO. Trabalho decente e juventude no Brasil. Brasília: OIT, 2012.

OLIVEIRA, S. R. Ponto de Partida: a juventude e o ingresso no mercado de trabalho. In: FERRAZ, D. L. S.; OLTRAMARI, A. P.; PONCHIROLLI, O. (org.). Gestão de pessoas e relações de trabalho. São Paulo: Atlas, p. 89-112, 2011.

O'REILLY, A.; GARRETT, P. M. "Playing the Game?": The sexual harassment of female social workers across professional workspaces. International Social Work, p. 1-14, 2017.

PAIVA, K. C. M. et al. Estresse ocupacional e burnout de jovens trabalhadores. Encontro Anual da Associação Nacional de Pós-Graduação e Pesquisa em Administração, XXXVII, 2013. Anais..., Rio de Janeiro: ANPAD, 2013.

PAMPLONA FILHO, R. M. V. O assédio sexual na relação de emprego. 2005. 343 f. Tese (Doutorado em Direito) - Pontifícia Universidade Católica de São Paulo, São Paulo, 2005.

POCHMANN, M. A inserção ocupacional e o emprego dos jovens. São Paulo: ABET, 1998.

PRATA, M. Assédio moral e assédio sexual: noções distintivas. In: Jus Navigandi. Abril de 2010. Disponível em https://jus.com.br/artigos/14675/assedio-moral-e-assedio-sexual-nocoes-distintivas/1. Acesso em 23 de abr. 2017. REIS, M. Uma análise da transição dos jovens para o primeiro emprego no Brasil. Revista Brasileira de Economia, v. 69, n. 1, p. 125-143, 2015.

SALVADOR, L. Assédio moral. Direito e justiça.: O Estado do Paraná S/A, Curitiba, p. 8-9, 2002.

SANTOS, A. Assédio Sexual nas Relações Trabalhistas e Estatuárias. $2^{a}$ ed. Rio de Janeiro: Forense, 2002.

SCHATZMAM. M; GOSDAL, T. C.; SOBOLL, L. A.; EBERLE, A. D. Aspectos definidores do assédio moral. In: SOBOLL, L. A.; GOSDAL, T. C. (orgs.). Assédio moral interpessoal e organizacional: um enfoque interdisciplinar. São Paulo: LTr, p. 17-30, 2009.

SCHMIDT, M. H. F. M. O assédio moral no direito do trabalho. Revista do Tribunal Regional do Trabalho da 9a Região, Curitiba, Serviço de Biblioteca e Jurisprudência, v. 27, n. 47, p. 177-227, 2002.

SCHNEIDER, K. T.; SWAN, S.; FITZGERALD, L. F. Job-related and psychological effects of sexual harassment in the workplace: Empirical evidence from two organizations. Journal of Applied Psychology, v. 82, n. 3, p. 401415, 1997.

SETTLES, I. H.; HARRELL, Z. A. T.; BUCHANAN, N. T.; YAP, S. C. Y. Frightened or bothered: Two types of sexual harassment appraisals. Social Psychological and Personality Science, p. 600-608, 2011.

SILVA, E. R. A. (coord.). Juventude e trabalho informal no Brasil. Organização Internacional do Trabalho. Brasília: OIT, 2015.

TANGRI, S. S.; BURT, M. R.; JOHNSON, L. B. Sexual Harassment at Work: Three Explanatory Models. Journal of Social Issues, v. 38, p. 33-54, 1982.

TEIXEIRA, J. C.; RAMPAZO, A. da S. Assédio sexual no contexto acadêmico da administração: não dito por que não vivenciado? Farol-Revista de Estudos Organizacionais e Sociedade, v.4, n.11, p.1151-1235, 2017.

TRIVIÑOS, A. N. S. Introdução à pesquisa em ciências sociais: a pesquisa qualitativa em educação. São Paulo, Atlas, 1987.

TUCKER, S.; LOUGHLIN, C. Young workers. In KELlOWAY, E. K., BARLING, J. \& HURRELL, J. (eds.). Handbook of Workplace Violence. Thousand Oaks: Sage, p. 417-444, 2006.

UNFPA. Direitos da população jovem: um marco para o desenvolvimento. $2^{\mathrm{a}}$ ed. Brasília: UNFPA - Fundo de População das Nações Unidas. 2010.

VELHO, G.; DUARTE, L. F. D. (org.). Juventude contemporânea: culturas, gostos e carreiras. Rio de Janeiro: 7 Letras, 2010.

VENTURI, G.; TORINI, D. Transições da escola para o trabalho dos jovens homens e mulheres no Brasil. Organização Internacional do Trabalho. Genebra: OIT, 2014.

VERGARA, S. C. Métodos de pesquisa em administração. $2^{a}$ ed. São Paulo: Atlas, 2006.

VERIGUINE, N. R.; BASSO, C.; SOARES, D. H. P. Juventude e Perspectivas de Futuro: A Orientação Profissional no Programa Primeiro Emprego. Psicologia: Ciência e Profissão, v. 34, n. 4, p. 1032-1044, 2014.

WICKERT, L. F. Desemprego e juventude: jovens em busca do primeiro emprego. Psicologia: ciência e profissão, v. 26, n. 2, p. 258-269, 2006. 